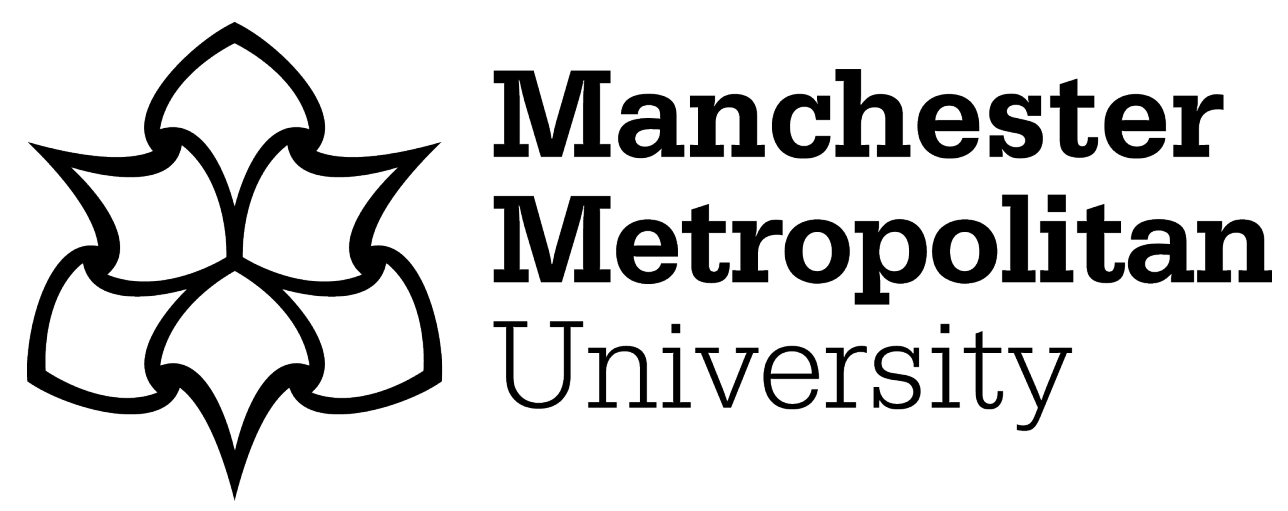

Witham, G and Haigh, C (2018) Narrative intelligence in nursing: storying patient lives in dementia care. Nursing Inquiry, 25 (3). pp. 1-10. ISSN 13207881

Downloaded from: https://e-space.mmu.ac.uk/620252/

Version: Accepted Version

Publisher: Wiley

DOI: https://doi.org/10.1111/nin.12244

Please cite the published version 
Witham G \& Haigh C (Authors copy): Narrative intelligence in nursing: storying patient lives in dementia care. Nursing Inquiry. Accepted 27/03/18

\title{
Narrative intelligence in nursing: storying patient lives in dementia care
}

\begin{abstract}
This paper examines narrative approaches to care within the context of dementia. It reviews the function of stories and explores some of the narrative genres that shape the cultural perceptions of dementia. We argue that narrative intelligence within healthcare is an important element in nurturing communal self-identity for people living with dementia. Listening and responding to stories and the cultural framework that this encompasses is an embodied action that is not just related to cognitive recall but situates us within a cultural community. People with dementia may have challenges in maintaining narrative legitimacy in the face of fractured stories and incoherent narratives. Health professionals can offer support in reframing and presenting counter stories that maintain identities that can potentially be marginalised, silenced and open to narrative foreclosure. This process requires health professionals to be attentive and responsive to how patients with dementia and their supporters construct and position the stories they tell and the meaning(s) they attach to them.
\end{abstract}


Witham G \& Haigh C (Authors copy): Narrative intelligence in nursing: storying patient lives in dementia care. Nursing Inquiry. Accepted 27/03/18

\section{Introduction}

There has been a call for a more narrative approach within healthcare and a need to challenge some of the biomedical approaches that appear not to address patient concerns (Bohlmeijer, Kenyon, \& Randall, 2011). Within this paradigm the importance of meaning and storytelling takes centre stage often rooted within a solidarity and emancipatory ethic. This paper focuses on narrative approaches to nursing care and how this can potentially be utilized within dementia support. Narrative approaches relate to the scientific method of inquiry, including narrative interviewing, naturalistic story gathering and organisational case studies (Greenhalgh, Russell, \& Swinglehurst, 2005). Narrative care rather relates to the clinical operationalising of these approaches as a therapeutic intervention or treatment (Baldwin, 2015). Narrative care has been described as story-telling to promote health and well-being (Baldwin, 2015) and although it remains a developing concept this paper will attempt to explore some of the major threads and tenants of both narrative approaches and narrative care and its application to dementia care. Dementia care is particularly important to focus on since stigma and negative social constructions of people with dementia are common within both the scientific community and media representations that often depict dementia as 'narratives of tragedy' (Basting, 2009). This has led people with dementia to attempt to normalise their experiences and avoid the framing of their social identity as an 'Alzheimer's patient' (Beard \& Fox 2008; Beard \& Neary, 2013). This fear and stigma related to dementia is commonly expressed in people living with mild cognitive impairment who wished to avoid the 'death sentence' diagnosis of dementia (Beard \& Neary, 2013). Dementia care is also important to focus on since there is a wide perception that, in people living with dementia, narrative foreclosure has ended life before death (Kaufman, 2006). Narrative care may present a particularly helpful approach in both addressing stigma and challenging the 'social death' 
Witham G \& Haigh C (Authors copy): Narrative intelligence in nursing: storying patient lives in dementia care. Nursing Inquiry. Accepted 27/03/18

(Sweeting \& Gilhooly, 1997) and further isolation and identity changes associated with living with dementia.

\section{Narrative approaches to care}

Greenhalgh and Hurwitz (1999) highlights the complementary nature of narrative approaches for evidence-based practice. She asserts that narrative frameworks do not challenge the hierarchy of evidence but rather evidence-based practice explicitly presupposes an interpretive element in situating the patient encounter within a unique context. Narrative methods can also be used in quality improvement research (Greenhalgh et al, 2005). Narrative approaches have been used in dementia care to explore individual care, for example, "reminiscence work" (Webster \& Haight, 2002), life story work (Buckley, McCormack, \& Ryan, 2013) or "storywork" (Randall, 2010). This ranges from individual to group work, biographical interviewing or memoir writing (Villar \& Serrat, 2017). The limitations of such approaches can be characterised by Berendonk and Caine (2016) who suggest that care staff, in relation to life story work, sought biographical information from relatives rather than the person with dementia because this was more reliable and "factual". Narratives become of secondary importance to biographical facts for care staff. Stories also may not sit comfortable with more task orientated nursing practice. Whilst acknowledging these specific narrative interventions we wish to explore narrative in more informal ways through everyday conversation (Norrick, 2010), since this represents the predominant way in which narrative shapes our social life (Reissman, 2008). These "small stories" (Georgakopoulou, 2006) provide opportunities to engage in narrative care and create meaningful communication within dementia care. 
Witham G \& Haigh C (Authors copy): Narrative intelligence in nursing: storying patient lives in dementia care. Nursing Inquiry. Accepted 27/03/18

\section{Narrative inquiry: what's in a story?}

Bruner $(1986,1996)$ described two modes of thought to frame and interpret our worldview: paradigmatic and narrative. A paradigmatic approach is grounded in science and philosophy and explored within formal education, whereas narrative is the primary mode in both literature and life. Paradigmatic thought seeks logical proof, empirical inquiry and hypothesis generation whereas narrative thought involves human intention and sense-making of the world we live in. It is to this mode of thought we explore and examine it through a performative narrative approach. A fundamental tenet of this ontological approach is to position our lives as 'storied' with identity narratively constructed. There are multiple truths, constructed by tellers who are socially and historically located (Bell, 2009; Reissman, 2003, 2008). This approach to narrative has what Smith and Sparkes (2008) describe as a 'thin individual' and 'thick social relational' focus in relation to the self and identities. The 'self' is not fixed, singular and coherent but rather storied selves and narrative identities are performative and therefore multiple, changing and unfixed. Language actively constructs the self, and it is through relationships that talk becomes the 'site' of self and identity work through a process of co-construction between speaker and listener. In stressing this performative element within communication is not to suggest that identities are inauthentic but only to acknowledge that they are situated and achieved within social relationships. As Riessman (2003) comments,

"Informants do not reveal an essential self as much as they perform a preferred one, selected from the multiplicity of selves or personas that individuals switch as they go about their lives." (p. 337)

The focus of narrative inquiry is diverse with Mattingley (1998) characterising the "eventness" (p.7) of stories with their human actions and plots. She asserts that narratives are 
Witham G \& Haigh C (Authors copy): Narrative intelligence in nursing: storying patient lives in dementia care. Nursing Inquiry. Accepted 27/03/18

both event centred and experience centred. They are not primarily a recall of past events but rather connect story and experience. Therefore, one of the primary areas of exploration is how social action develops into narrative form by the actors that take up this accounting. When patients enact stories they are accounting for meaning, they generate a plot from a series of otherwise meaningless chronological events and link this to a larger narrative whole. Lived experience is not linear but situated between a past and future and leads to an exploration of narrative time that conveys a position rather than a chronology (Frank, 1995; Bell, 2009). Narrative time can be defined as events generated from an unfolding temporal whole in which meaning is not identified at the end but rather emerges through the narrator as a whole through start beginning and end. Narrative form is underpinned by the lucidity of the characterisation of events and not just how it affirms or connects with the plot. Action and motive are integral structuring devices and often situated with desire to be in a different place. Narrative time is dramatic and similar to other authors it must be a story worth hearing, the 'tellability' (Och \& Capps, 2001) of a story is an essential element (Frank, 2010; Bruner, 1991). Endings are uncertain with narrative time steeped in suspense and often situated in trouble (Mattingley, 1998, 2010). Stories require action and are investigations of events and generate the ways in which practices are accounted for, constructed, negotiated and contested. Narratives are never neutral recalls of facts and events, there are no "unsponsored texts" (Harris, 1989) without intentionality and purpose. Frank (2012) views stories as either good or bad companions and as adapted, collected and (re)interpreted. They become material semiotic companions. Stories are never unique but are collected, more like "reassembled fragments on loan" (p.13) but still retain the genesis of standard character, plot and style in a recognised schema. Drawing on the work of Latour (2005), storytelling becomes a collective practice in which the social is constantly reassembled. The function of stories is important, what do they do and how is this enacted. This function is always dialogical involving 
Witham G \& Haigh C (Authors copy): Narrative intelligence in nursing: storying patient lives in dementia care. Nursing Inquiry. Accepted 27/03/18

multiple voices in their construction and at least two but usually three in the enactment, a story, a storyteller and a listener. So, for nurses, it is important to ask such questions as

- what can be learnt from storytellers and, in particular, what stories are silenced by other stories?

- Which stories fail to retain narrative alignment and when does the cultural imagination fail to recognise stories as enactments of resistance and jettison the validity of this type of narrative?

- If stories do the work of meaning, through performing memory, what narrative(s) become meaningless and therefore not useful?

Since stories are not neutral recalling of events then it is important to examine the consequences of the meanings attached to stories. Therefore, for example, if a story promotes the primacy of maintaining autonomy and independence then is this always useful for people living with dementia or can it diminish those narratives that emphasise and support the social networks that create the interdependency that is part of community life. It may silence those stories that are more appropriate to dementia care. Examining the available narrative resources and how these are manipulated, changed, adapted and re-told in stories are questions important in narrative inquiry. This process attends to our fears, dreams and desires, defining meaning(s) of life that we create and asking the question of what does it mean to live as a person? Narratives position our lives as 'storied' with identity narratively constructed. Nurses need to be attentive to the 'work' that stories do within interaction and encounters with patients (Frank, 2010).

\section{Biomedical narratives}

The framing of dementia within a biomedical context can present wider challenges for people living with dementia and their carers or supporters, particularly with the ambiguity associated 
Witham G \& Haigh C (Authors copy): Narrative intelligence in nursing: storying patient lives in dementia care. Nursing Inquiry. Accepted 27/03/18

with a medicalized discourse on cure and care (Chaufan, Hollister, Nazareno, \& Fox, 2012).

The framing of dementia as requiring expert intervention(s) often exclude carers with 'care' conceived as a series of treatment or behavioural management interventions that fail to include the narrative(s) of both the person with dementia and carer. This framing can be particularly problematic with the therapeutic nihilism associated with dementia and the tendency of biomedical approaches to focus on the individual to the exclusion of the wider social networks and mediators to which we belong. Radden and Fordge (2006) challenge this ideology of individualism that can isolate and define the subject in a way that compounds social isolation as they comment;

Consistency suggests that what was begun by others should be continued by them. And this point would not so readily be lost from sight were the distorting ideology of individualism which casts each person the master of their fate and captain of their soul to be replaced with more realistic, collectivist assumptions-as it surely should be. (p. 82)

People live in networks rather than isolated from the social context of life, however, contemporary healthcare appears concerned with refocusing to an individualistic, disease orientated approach that can be seen to negate both patient and carer involvement. This is reflected in the wider literature with Jurgens, Clissett, Gladman, and Harwood (2012) suggesting (on acute hospital admission of their relative) that some carers, on the basis of previous experience, sought to delay admission for their relative with dementia, concerned that the process would be more harmful than the physical illness. For carers the ward environment experience was variable, with concerns relating to symptoms and their cause, resisting early discharge, bed moves and lack of communication with professionals. There appeared a failure to address particular needs of the person with dementia or to seek information from family. Family carers thought staff were most concerned with delivering 
Witham G \& Haigh C (Authors copy): Narrative intelligence in nursing: storying patient lives in dementia care. Nursing Inquiry. Accepted 27/03/18

medical treatment and task-orientated care. Moyle, Borbasi, Wallis, Olorenshaw and Gracia, (2010) found very little meaningful nursing interaction, with task-orientated care predominating. Bauer, Fitzgerald and Koch, (2011a) and Bauer, Fitzgerald, Koch and King (2011b) examined hospital discharge as experienced by family carers of people with dementia. They identified a lack of information on the patient's condition, a need for education about ongoing care requirements including medications, symptom monitoring and management, greater psychological support and assistance in managing and negotiating care services. There was often a perception from carers that their knowledge of the care recipient was undervalued and the nature of the care delivery by hospital staff was a key driver in preparation for discharge. Mattingley (2010) presents a context underlining this apparent isolationist approach to patient care and she asserts there are three genres that often present in healing narrative emplotment(s) associated with biomedicine. They are healing as sleuthing, healing as battling disease and healing as repairing broken machine-bodies. They provide what Mattingley (2010) refers to as "an authorized action framework" (p. 54) in order to interpret both the narrative ground and expectations of how these healing dramas should unfold. In the enactment of this narrative structure "facts" or voices that do not coherently fulfil the narrative construct presented by the teller are side lined. In the first genre the sleuthing is constructed as a medical mystery to be solved and this can usually be enacted without recourse to family or friends or even the patient themselves since it can be solely diseased focused. The second cultural genre, healing as battling disease, the clinician and invading disease take centre stage. The body becomes the site of "battle" with clinicians fighting this disease process and is typically characterised by military metaphors, such as the 'war on cancer' (see Sontag, 1978). The final cultural genre, healing as machine repair is taken from Davis-Floyd and St. John (1998) interpretation of the body as a machine that can therefore be 'fixable'. It provides a mechanical metaphoric framework in which the clinician 
Witham G \& Haigh C (Authors copy): Narrative intelligence in nursing: storying patient lives in dementia care. Nursing Inquiry. Accepted 27/03/18

becomes an advanced mechanic able to remove, replace or adapt parts of the body that may have broken down. In all these three cultural genres both the person with dementia and the family/carers' can be side lined as superfluous to the healing process.

\section{Dementia and Selfhood- "the person in jeopardy"}

Without the engagement and cooperation of others within social context, there is no meaningful construction of 'selfhood'. Positioning and framing people with early stage of dementia, can, as Sabat and Harre (1992) indicate, "place a person in a certain amount of jeopardy" (p. 454). This jeopardy can be identified in two major limitations placed on narrative agency of people with dementia (Baldwin, 2009). Firstly, the narrowly defined nature of linguistic and narrative convention(s) and secondly the limited opportunities for narrativity with people living with dementia. As Bruner (2002) has commented;

"it is through narrative that we create and re-create selfhood.. if we lacked the capacity to make stories about ourselves, there would be no such thing as selfhood" (pp. 85-86).

These constraints identified are extrinsic and constructed rather than an integral part of a dementia diagnosis and highlight the (de)limiting narrativity that is constructed and imposed upon people living with dementia. Narratology involves linguistic moves that are on-going and construct meanings (Thornton, 2006) and Frank (2010) warns us that a life that is not narratable is vulnerable to devaluation, "Stories enact realities: they bring into being what was not there before, a life is effectively invisible until a story makes that life narratable" (p. 75). Baldwin (2009) calls for a "reconceptualising" of the issue(s) in order to maintain inclusivity within the narrative enterprise. The boundaries of linguistic conventions need addressing since to express oneself narratively there are clear requirements to situate oneself with narrative conventions. Memory loss, disorientation and a limited expressive language may render impossible a narrative engagement with the other. We also need to examine the 
Witham G \& Haigh C (Authors copy): Narrative intelligence in nursing: storying patient lives in dementia care. Nursing Inquiry. Accepted 27/03/18

meta-narratives of dementia that can define identity, for example, people living with dementia as 'empty shells', or just 'waiting to die' (Gorp \& Vercruysse, 2012). Johnstone (2013) further examines metaphors that are operationalised in relation to euthanasia and Alzheimer's disease and questions the context in which it is seen in metaphoric terms as an epidemic, a battle and a predatory thief metaphor in which the disease robs someone of their personhood. These construction(s) can limit opportunities of people living with dementia to contribute or be recognised as contributing to the narrative constructions of others. In moving from identity to cognition, the defining characteristic of selfhood that appear tied to cognition requires challenging. Persons as situated, embodied agents can act with purpose without explicit awareness or consciousness (Aquilina \& Hughes, 2006). Purposive relationships can develop and are often situated in an embedded context. Katz (2013) examines the historical context of dementia and personhood examining the medieval constructions of memory and the potential support of a more embodied approach that this perspective offers (Table 1).

\section{(Insert table 1)}

This interpretation of memory reminds us of our innate ability to emplot and story our lives in the presence of cognitive failure. The cognitive status of older people is part of the cognitive status of people at all ages because memory is adaptable at all ages. "Reducing people to their brains and isolating them as sick and marginal in the name of cognitive care harms memory, which is continual even when forgetful" (Katz 2013, p. 311). The pathologising of memory within a biomedical framework reduces memory problems to individual cognitive dysfunction rather than seeing the diverse context and form in which memory is transmitted and employed. This focus on issues of embodiment is also explored by Kontos (2005) who, like Aquilina and Hughes (2006), challenge the concept that maintenance of selfhood is through primarily socio-interactive engagement. It becomes more than just the ethical response of the other in relation to advance dementia as Radden and Fordge (2006) suggests 
Witham G \& Haigh C (Authors copy): Narrative intelligence in nursing: storying patient lives in dementia care. Nursing Inquiry. Accepted 27/03/18

but rather a full acknowledgement of humans as embodied beings. There remains a cultural 'script' embedded in complex social relationships. The implication of this is that individuals bring to social interaction, as Kontos (2005) asserts; "by virtue of their embodied nature a degree of intentionality and creativity that is ignored in person-centred care as it is currently practised" (p. 557). Smith (2009) uses Bourdieu's conceptualised habitus in relation to dementia. He defines habitus as a "system of personal dispositions that are constituted by lasting, acquired schemes of perception, thought and actions" (p. 38) and highlights the failure of habitus for those living with dementia. Habitus operates and is mediated within a cultural field, which becomes unintelligible to others as the dementia progresses. This then can potentially put people with dementia at risk of displacement from the cultural context to which they belong. There is a loss of a public form of the self and in a culturally highly regulated society any failure of habitus becomes a significant liability for individuals with dementia. Frank (2010) further explores narrative habitus and characterises this as situated in a repertoire of stories that must be culturally recognisable to both the person and the community in which it is located. It also facilitates a tacit knowledge of embodied practice in which the repertoire of stories are operationalised and understood. With narrative habitus this competence enables communities to recognise and predict the response to a particular story format. It also disposes a person's task in stories and (de)limits the future stories someone will be receptive too. Which stories a person responds and is receptive to out of all available stories provides their narrative habitus. Our response to a story is mostly tacit, embodied and predisposed (Frank, 2010). A person's predisposition is characterised by how stories should develop, fit and make sense. This functions in the recognition of stories and how this is taken up, stored and located in one's inner library of accumulative stories. People live in networks rather than isolated from the social context of life, however, contemporary healthcare appears 
Witham G \& Haigh C (Authors copy): Narrative intelligence in nursing: storying patient lives in dementia care. Nursing Inquiry. Accepted 27/03/18

concerned with refocusing to an individualistic, disease orientated approach that can be seen to negate carer involvement.

Bartlett and O'Connor (2007) contest the boundary of personhood in that they challenge the extent to which this conceptualisation promotes agency, if it is endowed upon someone with dementia then it is a category assigned, the person becomes a passive recipient dependent on external validation. It is bestowed by the cognitively intact and minimises the social agency of people living with dementia. Notions of personhood would seem to need further exploration and Nolan, Davies, Brown, Keady, and Nolan (2004) use the framework developed by Mulrooney (1997, as cited in Nolan et al, 2004), in order to move away from concepts of personhood based on an understanding of autonomy as independence and individualism. The 'Senses Framework' (Nolan, Davies, \& Grant, 2001; Nolan, Davies, Brown, Keady, \& Nolan, 2002) attempts to present and capture a more multi-faceted view of caring relationships incorporating both interpersonal processes and intra-personal experiences of giving and receiving care. All parties involved should experience relationships that promote a sense of security, belonging, continuity, purpose, achievement and significance. For caregivers respect for personhood is associated with both a value for interdependence and investment in caregiving as a choice. It would seem important to acknowledge the 'multiple voices' that exist within caregiving relationships and developing strategies in which carers, health professionals and people living with, for example, dementia, can be meaningfully involved within different complex environments. Dementia care is often provided within these dementia care triads and the interplay of conversational and social practices undertaken by dementia care triad members can position each other in certain ways (Adams \& Gardiner, 2005). To deliver personalised care nurse engagement needs to work with these 'multiple voices'. This often requires proactive facilitation of carers by nurses related to decisionmaking and care choices within the context of dementia care. Decision-making with the 
Witham G \& Haigh C (Authors copy): Narrative intelligence in nursing: storying patient lives in dementia care. Nursing Inquiry. Accepted 27/03/18

person living with dementia and their carer/supporter is complex; requiring negotiation and nuanced communication that often needed adaptation dependent on the severity of the cognitive impairment (Miller, Whitlatch, \& Lyons, 2016). These discussions need wider appreciation of the barriers for carers including the denial of the problem and rejection of help from the person with dementia, and from health professionals the failure to recognise the problems, the subsequent late diagnosis and the timing and quantity of information given. Claims to confidentiality and data protection as well as bureaucracy and rigidity also meant that carers' ability to make decisions can sometimes be compromised (Livingston et al, 2010; Lord, Livingston, \& Cooper, 2015).

Katz (2013) description of a medieval perspective of embodiment may present a more helpful construction than post Cartesian mind/body split in supporting positive cultural framing for carers and people with dementia. If personhood is defined and located in the mind, biomedical narratives can exacerbate and perpetuate a reductionist interpretation of personhood that positions narrative foreclosure as an inevitable consequence of advancing dementia. People with dementia and their supporters have to negotiate and function in the shadows and borders of narrative possibilities, advocating and positioning themselves or their care recipient in a positive cultural light. This cultural framing is explicit and implicit within dialogue with health professionals and opening up spaces and counter narratives (Nelson, 2001) is an important element of resistance to biomedical discourses.

Our narrative lives are often presented/perceived as coherent, unique and unified but as Butler (2005) reminds us the "I" has no story of its own external to our relational lives and a set of norms that govern such as life. Illness and particularly life limiting conditions challenge the artificial constructions we generate from the cultural framing available to us. It highlights and positions the vulnerability of people with dementia and their supporters and drives the ethical imperative of remembering the old self since recalling biographical 
Witham G \& Haigh C (Authors copy): Narrative intelligence in nursing: storying patient lives in dementia care. Nursing Inquiry. Accepted 27/03/18

fragments signifies both their moral agency and fully developed interacting self that historically existed (Karner \& Bobbitt-Zeher, 2006).

\section{Narrative care and dementia}

Narrative care privileges the stories and narratives people tell in order to interpret, contextualise and make sense of the disruption(s) that illness and disability cause. This is relational and grounded in the cultural discourses that shape and structure our lives. Narrative care develops a "language of opening" that serves as a counterpoint to the medical model's "language of limits" (Vittona, 1999). Vittona (1999) reports on the nursing assistant's use of language in a residential facility for people living with dementia. This paper highlights how care staff use a process of;

"naming and refraining to construct a set of social meanings that depict the residents as a socially responsive actor with a surviving self that is living, not just waiting to die”. (p. 362)

This process was a nuanced counter narrative, positioning experience, indigenous knowledge and the empirical world to sustain personhood in the face reductionist of biomedical interpretations. It also situated the lived experience within the context of a dedicated care facility organised around biomedical presuppositions about the nature of dementia care. This reframing was characterised by the "local knowledge" that guided the care of residents as well as general attitudes of staff towards the care home. The nursing assistants were able to generate a narrative life for residents and were aware of the embodied language of individuals interpreting those meanings and engaging in a dialogue with the resident. The language of openings typified the staff's way of talking, being and doing in maintaining personhood, for example, the language of 'wandering' was reframed to focus on 'getting busy', 'moving and 'walking'. Vittona (1999) comments that this; 
Witham G \& Haigh C (Authors copy): Narrative intelligence in nursing: storying patient lives in dementia care. Nursing Inquiry. Accepted 27/03/18

“alternative language reflects what I will call 'rhythms of the social world' of the residents, where movements are far from meaningless or aimless". (p. 371)

The biomedical framing within medical encounters is a key concern within narrative care. Frank (2004) highlights a protocol driven system that fails to examine the cultural frame in which it is heard. If the answer to a question does not fit with health professional expectations then patients could face difficulty getting the care needed. Mattingley (2008) reminds us that narrative is connected to our capacity to read other minds, what she describes as narrative mind reading. Interpreting intentions is precipitated upon our capacity to situate actions within unfolding narrative frames. The interpretive act requires a capacity to assign motive within a situated unfolding story Mattingley (2008). One must be able to categorise or recognise an action within some sort of historical context in order to make it intelligible, it must be positioned within a culturally shared story. Narrative mind reading becomes an everyday necessity in sense-making and is culturally situated and integral to the production of cultural knowledge. When we are in a context where there is ambiguity and uncertainty, when it is not clear why people are acting in a certain way or what exactly is going on, then a failure in narrative mind reading may occur. When clinical interchanges do not go well it is often because of misreading(s). The complexities of care are often minimised within formal health care interactions and this can create narrative foreclosure and ineffective support. Clissett, Porock, Harwood, and Gladman (2013) identified the importance of 'attachment' and connecting with people living with dementia founded on continuity of staff, the communication skills of the individual members of staff and whether they recognised the relationships that matter to the person with dementia. This affirms the work of Edvardsson, Fetherstonhaugh, and Nay (2010) who assert that for people with dementia it may be more important that the experience of a task is positive than that it is completed efficiently. The "warmth of reciprocity" (Ryan, Spykerman, \& Anas , 2005, p.33) would typify the intention 
Witham G \& Haigh C (Authors copy): Narrative intelligence in nursing: storying patient lives in dementia care. Nursing Inquiry. Accepted 27/03/18

of these activities. Narrative care is often opportunistic in nature and incorporated in routine caring tasks. Norman (2006) again affirms the importance of nurses' perceptions of people living with dementia that can lead to the constraint or realisation of a person's portrayal of self.

A clinical example would be health professionals attempt to assess the challenging behaviour of someone with a chest infection and living with dementia in a ward setting. The medical team may follow a common script of "healing as sleuthing" (Mattingley, 2010) in attempting to make a diagnosis as to the cause. This may be diametrically opposite from the narrative of the patient or carers and it does not merely represent a misreading of storylines, a misinterpretation by the consultant. The medical team is almost inevitably drawn into the plot of a problem patient because of a number of competing circumstances. A plot of a "troublesome familiar stranger" (Mattingley, 2008, p.145) in which the characters are presented as acting in predictable but unreasonable, unaccountable and possibly immoral ways. They are wishing to heal this patient of the chest infection but this appears compromised by the aggressive, irrational behaviour of this person. Their characters are rendered flat, stereotypical and nameless. Another example from Mattingley (2008) is how medical charts function and operate. Medical charts, like many nursing documentation are records of small moments here and there, they are highly abbreviated, multiply authored and string together short happenings without an integrated, coherent narrative plot. The complex narrative meaning(s) that stories our lives are replaced by a series of "nows" that are separate and discrete. It generates a clinical gaze that is impervious and actively excludes motives. The evaluation of actions and subsequent consequences are disconnected from a narrative cultural frame. Mattingley (2008) asserts that: 
Witham G \& Haigh C (Authors copy): Narrative intelligence in nursing: storying patient lives in dementia care. Nursing Inquiry. Accepted 27/03/18

"Because actual humans are not flat, narratives that portray them in this way can only be told if there are discursive strategies that allow "real life" storytellers to ignore a great deal of what is actually done and said". (p. 147)

Charon (2006) has also reflected on the hospital chart as a genre highlighting the controlled dictum, the prescribing of the grammatical tense and voice in which to write and record to the exclusion of emotion. By identifying a text's temporal scaffolding one can highlight the narrative silencing that routinely occurs within formalised health care. Biomedical framing by this process often excludes the moral agency of all human agents. There is not the presentation of a counter narrative described by Nelson (2001) but rather a refusal of narrative itself and the presentation of a chronicle in which it describes one thing after another not one thing because of another. Kirmayer (2000) refers to this process as the creation of an ideological account, this turning and reconstruction of narrative gives a specific kind of coherence to a story. It also gives the health professional technical control over both interpretation and continuation of the story and reinforces the reality to which it draws its structure. Frank (2015) comments that for effective narrative care it requires proximity, the being there and listening to the stories to which we interpret our lives. This process is actively hampered by healthcare organisations in which honouring this commitment is troubled by persistent territorial disruptions over who stays how long and does what. It defines and tightly categories who patients and health professionals can be to and for each other (Frank, 2015).

\section{Narrative Intelligence}

Randall (1999) refers to narrative intelligence, in relation to biological ageing, as the capacity to formulate and to follow the story of our own lives. This narrative intelligence is innate and universal as we make sense of the world through story-making (Randall, 2014). A nurse's ability to "read" narratives and cues from stories in everyday conversation is an integral part 
Witham G \& Haigh C (Authors copy): Narrative intelligence in nursing: storying patient lives in dementia care. Nursing Inquiry. Accepted 27/03/18

of narrative care. Charon (2004) develops this and refers to health professionals developing narrative competence within daily practice and she defines this as the;

set of skills required to recognise, absorb, interpret and be moved by the stories one hears and reads. This competence requires a combination of textual (identifying a story's structure, adapting its multiple perspectives, recognising metaphors and allusions), creative skills (imagining among interpretations, building curiosity, inventing multiple endings) and affective skills, (tolerating uncertainty as a story unfolds, entering the story's mood. (p. 863)

Within this context, competence is not predicated on a set of pre-determined standards suggestive of the biomedical model but rather competence is the development of a reflexive process that attempts to situate stories within the context and meanings that people generate in order to make sense of the circumstances presented. Stories are never unique but are adapted and modified from a series of culturally derived narratives (Frank, 2010). In this sense, narrative competence becomes the ability to co-create, to co-imagine health care decisions that reflect both scientific knowledge and metaphoric or narrative knowledge by which we generate meaning within life events. We can co-create because stories must be culturally understandable to make sense and so we share these narrative frameworks as a community, whether we are health professionals, carers or patients. We can therefore recognise and respond and often adapting and re-interpret these stories in our response to hearing them. Charon (2006) examines narrative knowledge within a healthcare context and suggests that such an approach requires candid reflection and an active listening to the stories that frame one's life. She characterises the differences in approach between patient and health professional with the former perceiving illness within the narrative framing of their whole life whereas the later tend to designate illness within discrete, isolated events framed as biological puzzles requiring expert medical or behavioural interventions. Charon (2006) 
Witham G \& Haigh C (Authors copy): Narrative intelligence in nursing: storying patient lives in dementia care. Nursing Inquiry. Accepted 27/03/18

suggests there are five narrative features of medicine including temporality, singularity, causality/contingency, intersubjectivity and ethicality (Table 2).

(Inset Table 2)

One of the features characterised by Charon (2006) and an approach relevant to all health professionals is the challenge to biomedical narratives that universalize and replicate rather than focus on the particular patient, demanding to know how a disease uniquely affects them, "what is different about this disease as it manifests itself in this particular patient?" (p. 27). The challenge remains for health professionals to mediate through the contradictory impulse to both maintain and honour the unique components of narrative construction and the requirement to generate observations that are 'readable' in a range of health care setting and personnel. Emplotment challenges the restrictive nature of medical discourses and is inclusive, highlighting the uniqueness of patient encounters accounting for contingency and difference. Emplotment occurs throughout clinical practice, from diagnosis to nursing interventions and care plans. They are ways to manage and quantify a plot from an apparent disparate series of events or states of affairs. The categorisation of these set of events make it medically recognisable. The intersubjective situation is often based on complex texts shared between patient and health professional involving silences, words, physical findings and examination(s). Ethicality is embed in stories since they are purposive and reflect on how to live. These demand the listener to engage and present an answer; what is good or bad and how ought we act and be as moral agents? (Frank, 2010). Narrative care can ultimately open up the storied lives of people with dementia in a way that engages with the meaning(s) to which we attach to the disease process that confront us. In doing so this becomes a joint venture in creating hope, opening up silences and examining the contexts in which we live. If health professionals can honour this inter-subjectivity then as Charon (2006) suggests; 
Witham G \& Haigh C (Authors copy): Narrative intelligence in nursing: storying patient lives in dementia care. Nursing Inquiry. Accepted 27/03/18

They will know their patient's beliefs and wishes regarding end of life, if only as part of what they learn of their temporality. They will more regularly enter robust intersubjective relationships with their patients, knowing with more accuracy and authenticity than other health care professionals do about what denotes meaning in each patient's life... the ethicality of narrative medicine that is to say, emerges directly and organically from its practice and need not have a separate 'bioethics' function appended to it. (p. 210)

The clinical borderlands of care are situated in encounters where two or more cultures edge each other, they retain the properties of fluidity, identity making and potential marginalisation as cultural (mis)recognition can silence alternative narrative resources (Mattingly, 2010). The ambiguous and contradictory nature of multiple cultural frames needs to be navigated within clinical encounters in order to prevent foreclosure of positive companion stories that support the making of self. For this to occur health professionals need to be attentive to metaphor, allegory and how patients with dementia and their supporters tell the stories of events and how they interpret this within their autobiography. An embodied understanding of dementia (Kontos, 2005; Katz, 2013) moves from personhood as an attribute bestowed on someone and acknowledges that stories are deeply embedded in our cultural frames, are tacit and predispose our interpretation of events. Therefore, even if someone with dementia loses the ability to articulate this through language there is an intentionality grounded in narrative genres that generate stories and culturally frame our lives. Clinically, this can be enacted by nurses understanding an individual's embodied narrative (Randall \& Mc Kim, 2008) which can be enabled through supporting the person's preferred activities or clothing habits to situate them within their previous chosen cultural frame. Nurses can also establish the individual's current conversation practices and then work with this to further engage with the 
Witham G \& Haigh C (Authors copy): Narrative intelligence in nursing: storying patient lives in dementia care. Nursing Inquiry. Accepted 27/03/18

person living with dementia (Kindell, Keady, Sage, \& Wilkinson, 2017). Casual conversation promotes positive social between individual with dementia (Mok \& Muller 2014). This is important because even with advanced dementia there is evidence of turn-taking in conversation (Mikesell, 2009), routine sequences (Kitzinger \& Jones, 2007) attempts to repair conversations (Muller \& Guendouz, 2005) and the deployment of laughter as a strategy to establish competency (Lindholm, 2008). This is a process that is more than a mere cognitive ability or memory retrieval but is embodied in emotion, action and communal living (Kontos, 2005). Narrative care is nuanced. It is not merely operationalised by such interventions as dementia reminiscence therapy to explore our storied lives. It is actively seeking and supporting how people navigate stories, interpret them, use them and adapt them in attempting to address how to live in the face of chronic illness and frailty. It requires "small stories" (Berendock, Blix, Randall, Baldwin, \& Caine, 2017) that can connect and become sense-making.

\section{Conclusion}

Narrative mind reading (Mattingley, 2008) is required by health professionals to avoid positioning people with dementia as 'flat' characters whose self-narrative becomes an insignificant sub text to the plot of diagnosis, treatment and recovery. Addressing these issues are complex and require listening and being attentive to the silencing of patients narratives and the networks that hold and nurture the human identity that stories provide. Health transformation starts with small stories, counter narratives that position themselves, gain traction and agitate for change in the face of narrative silencing. Active listening by health professionals can facilitate this process and provide support that challenge master narratives of biomedicine that may hinder narrative expression. 
Witham G \& Haigh C (Authors copy): Narrative intelligence in nursing: storying patient lives in dementia care. Nursing Inquiry. Accepted 27/03/18

\section{References}

Adams, T., \& Gardiner, P. (2005). Communication and Interaction within dementia care triads. Dementia, 4(2), 185-205. https://doi.org/10.1177/1471301205051092

Aquilina, C., \& Hughes, J.C. (2006). The return of the living dead: agency lost and found? In J. C. Hughes, S. J. Louw \& S. R. Sabat (Eds.), Dementia: Mind, Meaning and the Person. (pp. 143-161). Oxford: Oxford University Press.

Baldwin, C. (2009). Narrative \& decision-making. In D. Connor \& B. Purves (Eds.), Decision-making, Personhood \& Dementia: Exploring the Interface (pp. 25-36). London: Jessica Kingsley Publishers.

Baldwin, C. (2015). Narrative ethics for narrative care. Journal of Aging Studies, 34, 183189. https://doi.org/10.1016/j.jaging.2015.02.014

Bauer, M., Fitzgerald, L., \& Koch, S. (2011a). Hospital discharge as experienced by family carers of people with dementia: a case for quality improvement. Journal for Healthcare Quality, 33(6), 9-16. https://doi.org/10.1111/j.1945-1474.2011.00122.x

Bauer, M., Fitzgerald, L., Koch, S., \& King, S. (2011b). How family carers view hospital discharge planning for the older person with a dementia. Dementia, 10(3), 317-323.

https://doi.org/10.1177/1471301211407790

Bartlett, R., \& O’Connor, D. (2007). From Personhood to Citizenship: Broadening the lens of dementia practice and research. Journal of Aging Studies, 21(2), 107-118.

https://doi.org/10.1016/i.jaging.2006.09.002

Basting, A.D. (2009). Forget Memory: Creating Better Lives For People with Dementia. Baltimore: Johns Hopkins University Press. 
Witham G \& Haigh C (Authors copy): Narrative intelligence in nursing: storying patient lives in dementia care. Nursing Inquiry. Accepted 27/03/18

Beard, R.L., \& Fox, P.J. (2008). Resisting social disenfranchisement: negotiating collective identities and everyday life with memory loss. Social Science \& Medicine, 66(7), 1509-1520. https://doi.org/10.1016/j.socscimed.2007.12.024

Beard, R.L., \& Neary, T.M. (2013). Making sense of nonsense: experiences of mild cognitive impairment. Sociology of Health \& Illness, 35(1), 130-146. https://doi.org/10.1111/j.1467$\underline{9566.2012 .01481 . x}$

Bell, S.E. (2009). DES Daughters: Embodied Knowledge and the Transformation of Women's Health Politics. Philadelphia: Temple University Press.

Berendonk, C., \& Caine, V. (2016). Life story work with persons with dementia in nursing homes: A grounded Theory study of the perspectives of care staff. Dementia, doi: $10.1177 / 1471301216669236$.

Berendonk, C., Blix, B.H., Randall, W.L., Baldwin, C., \& Caine, V. (2017). Care as narrative practice in the context of long-term care: Theoretical Considerations. International Journal of older People Nursing, doi:10.111/opn.12156

Bohlmeijer, E., Kenyon, G., \& Randall, W.L. (2011). Towards a Narrative Turn in healthcare. In G. Kenyon, E. Bohlmeijer \& W.L. Randall (Eds.), Storying later life, issues, investigations and interventions in narrative Gerontology (pp. 366-380). Oxford: Oxford University Press.

Buckley, C., McCormack, B., \& Ryan, A. (2013). Valuing narrative in the care of older people: A framework of narrative practice for older adult residential care settings. Journal of Clinical Nursing, 23, 2565-2577. https://doi.org/10.1111/jocn.12472

Butler, J. (2005). Giving an Account of Oneself. New York: Fordham University Press.

Bruner, J. (1986). Actual Minds, Possible Worlds. Cambridge MA: Harvard University Press. 
Witham G \& Haigh C (Authors copy): Narrative intelligence in nursing: storying patient lives in dementia care. Nursing Inquiry. Accepted 27/03/18

Bruner, J. (1991). The Narrative Construction of Reality. Critical Inquiry, 18, 1-21.

https://doi.org/10.1086/448619

Bruner, J. (1996). The Culture of Education. Cambridge MA: Harvard University Press.

Bruner, J. (2002). Making stories: Law, Literature, Life. New York: Farrar, Straus and Giroux.

Chaufan, C., Hollister, B., Nazareno, J., \& Fox, P. (2012). Medical ideology as a doubleedged sword: the politics of cure and care in the making of Alzheimer's disease. Social Science \& Medicine, 4(5), 788-795. https://doi.org/10.1016/j.socscimed.2011.10.033

Charon, R. (2004). Narrative \& Medicine. New England Journal of Medicine, 350, 862-864.

Doi: $10.1056 /$ NEJMp038249

Charon, R. (2006). Narrative Medicine; Honoring the stories of illness. Oxford: Oxford University Press.

Clissett, P., Porock, D., Harwood, R.H., \& Gladman, J.R.F. (2013). The challenges of achieving person-centred care in acute hospitals: a qualitative study of people with dementia and their families. International Journal of Nursing Studies, 50, 1495-1503. https://doi.org/10.1016/j.ijnurstu.2013.03.001

Davis-Floyd, R.E., \& St John, G. (1998). From Doctor to Healer: The Transformative Journey. London: Rutgers University Press.

Edvardsson, D., Fetherstonhaugh, D., \& Nay, R. (2010). Promoting a continuation of self and normality: person - centred care described by people with dementia, their family members and aged care staff. Journal of Clinical Nursing, 19(17/18), 2611-2618. https://doi.org/10.1111/j.1365-2702.2009.03143.x 
Witham G \& Haigh C (Authors copy): Narrative intelligence in nursing: storying patient lives in dementia care. Nursing Inquiry. Accepted 27/03/18

Frank, A. W. (1995). The wounded storyteller: Body, illness and Ethics. London: The University of Chicago Press.

Frank, A. W. (2010). Letting stories breathe: a socio-narratology. London: The University of Chicago Press.

Frank, A. W. (2012). Practising Dialogical Narrative Analysis. In J.A. Holstein \& J. F. Gubrium (Eds.), Varieties of Narrative analysis (pp. 33-52). London: Sage.

Frank, A. W. (2015). Asking the Right Questions about Pain: Narrative and Phronesis. British Journal of Pain, 9(1), 209-225. 10.1353/1m.2005.0003

Georgakopoulou, A. (2007). Thinking big with Small Stories in narrative and identity analysis. In M. Bamberg (ed.), Narrative State of the Art (pp.145-154). Amsterdam: John Benjamins Publishing.

Gorp, van. B., \& Vercruysse, T. (2012). Frames and counter-frames giving meaning to dementia: A framing analysis of media content. Social Science \& Medicine, 74, 1274-1281. https://doi.org/10.1016/j.socscimed.2011.12.045

Greenhalgh, T., \& Hurwitz, B. (1999). Narrative based Medicine: Why study narrative? British Medical Journal, 318, 48-50. https://doi.org/10.1136/bmj.318.7175.48

Greenhalgh, T., Russell, J., \& Swinglehurst, D. (2005). Narrative methods in quality improvement research. Quality Safety Health Care, 14, 443-449. http://dx.doi.org/10.1136/qshc.2005.014712

Harris, R. (1989). “How Does Writing restructure Thought?” Language and Communication, 9 (2/3), 99-106. https://doi.org/10.1016/0271-5309(89)90012-8

Johnstone, M.J. (2013). Metaphors, stigma and the 'Alzheimerization' of the euthanasia debate. Dementia, 12(4), 371-393. https://doi.org/10.1177/1471301211429168 
Witham G \& Haigh C (Authors copy): Narrative intelligence in nursing: storying patient lives in dementia care. Nursing Inquiry. Accepted 27/03/18

Jurgens, F.J., Clissett, P., Gladman, J.R.F., \& Harwood, R.H. (2012). Why are family carers of people with dementia dissatisfied with general hospital care? A qualitative study. $B M C$ Geriatrics, 12:57 doi:10.1186/1471-2318-12-57.

Kaufman, S.R. (2006). Dementia-near-Death and life itself. In A. Leibing \& L. Chen (Eds.), Thinking about dementia, culture, loss and the anthropology of Senility (pp. 23-42). London: Rutgers University Press.

Karner, T., \& Bobbitt-Zeher, D. (2006). Losing Selves: dementia care as disruption and transformation. Symbolic Interaction, 28(4), 549-70. https://doi.org/10.1525/si.2005.28.4.549

Katz, S. (2013). Dementia, personhood and embodiment: what can we learn from the medieval history of memory? Dementia, 12(3), 303-314.

https://doi.org/10.1177/1471301213476505

Kindell, J., Keady, J., Sage, K., \& Wilkinson, R. (2017). Everyday conversation in dementia: a review of the literature to inform research and practice. International Journal of Language Communication Disorder, 52(4), 392-406. https://doi.org/10.1111/1460-6984.12298

Kirmayer, L.J. (2000). Broken Narratives, Clinical Encounters and the poetics of illness Experience. In L. C. Garro \& C. Mattingley (Eds.), Narrative and the cultural Construction of illness and healing (pp. 153-181). London: University of California Press Ltd.

Kitzinger, C., \& Jones, D. (2007). When may calls home: The opening moments of family telephone conversations with an Alzheimer's patient. Feminism and Psychology, 17(2), 184202. DOI: $\underline{10.1177 / 0959353507076550}$

Kontos, P.C. (2005). Embodied Selfhood in Alzheimer's disease. Dementia, 4(4), 553-570. https://doi.org/10.1177/1471301205058311 
Witham G \& Haigh C (Authors copy): Narrative intelligence in nursing: storying patient lives in dementia care. Nursing Inquiry. Accepted 27/03/18

Latour, B. (2005). Reassembling the Social: An Introduction to Actor-Network Theory.

Oxford: Oxford University Press.

Lindholm, C. (2008). Laughter. Communication problems and dementia. Communication and Medicine, 5, 3-14. DOI: $10.1558 /$ cam.v5i1.3

Livingston, G., Leavey, G., Manela, M., Livingston, D., Rait, G., Sampson, E.,... \& Cooper, C. (2010). Making decisions for people with dementia who lack capacity: qualitative study of family carers in UK. BMJ, 341:c4184 doi:10.1136/bmj.c4184.

Lord, K., Livingston, G., Cooper, C. (2015). A systematic review of barriers and facilitators to and interventions for proxy decision-making by family carers of people with dementia. International Psychogeriatrics, 27(8), 1301-1312.

https://doi.org/10.1017/S1041610215000411

Mattingley, C. (1998). Healing dramas and Clinical Plots: The narrative structure of experience. Cambridge: Cambridge University Press.

Mattingley, C. (2008). Reading Minds. Ethos, 136-154. https://doi.org/10.1111/j.15481352.2008.00008.x

Mattingley, C. (2010). The Paradox of Hope: Journeys through a Clinical Borderland. London: University of California Press Ltd.

Mikesell, L. (2009). Conversational practices of a frontotemporal dementia patient and his interlocutors. Research on Language and Social Interaction, 48, 176-199. https://doi.org/10.1080/08351810902864552

Miller, L.M., Whitlatch, C.J., \& Lyons, K.S. (2016). Shared decision-making in dementia: a review of patient and family carer involvement. Dementia, 15(5), 1141-1157.

https://doi.org/10.1177/1471301214555542 
Witham G \& Haigh C (Authors copy): Narrative intelligence in nursing: storying patient lives in dementia care. Nursing Inquiry. Accepted 27/03/18

Mok, Z., \& Muller, N. (2014). Staging casual conversations for people with dementia.

Dementia, 13(6), 834-853. https://doi.org/10.1177/1471301213488609

Moyle, W., Borbasi, S., Wallis, M., Olorenshaw, R., \& Gracia, N. (2010). Acute care management of older people with dementia: a qualitative perspective. Journal of Clinical Nursing, 20, 420-428. https://doi.org/10.1111/j.1365-2702.2010.03521.x

Muller, N., \& Guendouzi, J. A. (2005). Older and disorder in conversation: encounters with dementia of the Alzheimer's type. Clinical Linguistics and Phonetics, 19, 393-404. https://doi.org/10.1080/02699200400027213

Nelson, H. L. (2001). Damaged identities: narrative repair. London: Cornell University Press.

Nolan, M.R., Davies, S., \& Grant, G. (eds.) (2001). Working with Older People and their Families: Key Issues in Policy and Practice. Buckingham: Open University Press.

Nolan, M.R., Davies, S., Brown, J., Keady, J., \& Nolan, J. (2002). Longitudinal Study of the Effectiveness of Educational Preparation to Meet the Needs of Older People and Carers: The AGEIN (Advancing Gerontological Education in Nursing) Project. London: English National Board for Nursing, Midwifery and Health Visiting, 320.

Nolan, M.R., Davies, S., Brown, J., Keady, J., \& Nolan, J. (2004). Beyond 'person-centred' care: a new vision for gerontological nursing. International Journal of older people Nursing in association with Journal of Clinical Nursing, 13, 3a, 45-53. https://doi.org/10.1111/j.1365$\underline{2702.2004 .00926 . x}$

Norman, R. (2006). Observations of the experiences of people with dementia on general hospital wards. Journal of Research in Nursing, 11(5), 453-465.

https://doi.org/10.1177/1744987106065684 
Witham G \& Haigh C (Authors copy): Narrative intelligence in nursing: storying patient lives in dementia care. Nursing Inquiry. Accepted 27/03/18

Norrick, N.R. (2010). Conversational Narrative: storytelling in everyday talk. Amsterdam: John Benjamins Publishing Company.

Ochs, E., \& Capps, L. (2001). Living Narrative: creating lives in Everyday Storytelling. London: Harvard University Press.

Radden, J., \& Fordge, J.M. (2006). Into the darkness: losing identity with dementia. In J. C. Hughes, S.J. Lovw \& S.R. Sabat (Eds.), Dementia, mind, meaning and the person (pp.71-88). Oxford: Oxford University Press.

Randall, W. L. (1999). Narrative intelligence and the novelty of our lives. Journal of Aging Studies, 13(1), 11-28. https://doi.org/10.1016/S0890-4065(99)80003-6

Randall, W. L., \& McKim, E. (2008). Reading our lives. The poetics of growing old. Oxford: NY University Press.

Randall, W. L. (2010). The narrative complexity of our past: In praise of memory's sins. Theory \& Psychology, 20(2), 147-169. http://dx.doi.org/10.1177/0959354309345635

Randall, W. L. (2014). The stories we are: An essay on self-creation ( $2^{\text {nd }}$ Ed). Toronto: University of Toronto Press.

Riessman, C.K. (2003). Performing identities in illness narrative: masculinity and multiple sclerosis. Qualitative Research, 3, 5-33. https://doi.org/10.1177/146879410300300101

Riessman, C.K. (2008). Narrative Methods for the Human Sciences. London: Sage.

Ryan, E. B., Spykerman, H., \& Anas, A.P. (2005). Writers with dementia: The interplay among reading, writing and personhood. In B.H. Davis (ed.), Alzheimer's talk, text and context: Enhancing communication (pp 190-198). New York: Palgrave MacMillan. 
Witham G \& Haigh C (Authors copy): Narrative intelligence in nursing: storying patient lives in dementia care. Nursing Inquiry. Accepted 27/03/18

Sabat, S.R., \& Harre, R. (1992). The Construction and deconstruction of Self in Alzheimer's

Disease. Ageing and Society, 12, 443-461.

https://doi.org/10.1017/S0144686X00005262

Smith, A. (2009). Decision-making as Social Practice. Exploring the relevance of Bourdieu's concepts of habitus and symbolic capital. In D. O’Connor \& B. Purves (Eds.) Decisionmaking, Personhood and dementia: Exploring the interface (pp. 37-46). London: Jessica Kingsley Publishers.

Smith, B., \& Sparkes, A.C. (2008). Contrasting perspectives on narrating selves and identities: an invitation to dialogue. Qualitative Research, 8, 5-35.

https://doi.org/10.1177/1468794107085221

Sontag, S. (1978). Illness as Metaphor. New York: Vintage.

Sweeting, H., \& Gilhooly, M. (1997). Dementia and the phenomenon of social death. Sociology of Health \& Illness, 19(1), 93-117. https://doi.org/10.1111/j.14679566.1997.tb00017.x

Thornton, T. (2006). The discursive turn, social constructivism and dementia. In In J. C. Hughes, S.J. Lovw \& S.R. Sabat (Eds.), Dementia, mind, meaning and the person (pp.123141). Oxford: Oxford University Press.

Villar, F., \& Serrat, R. (2017). Changing the culture of long-term care through narrative care: Individual, interpersonal and institutional dimensions. Journal of Aging Studies, 40, 44-48. https://doi.org/10.1016/j.jaging.2016.12.007

Vittoria, A. K. (1999). “Our own little language”: Naming and the Social Construction of Alzheimer's Disease, Symbolic Interaction, 22(4), 301-384. https://doi.org/10.1016/S0195$\underline{6086(00) 87402-0}$ 
Witham G \& Haigh C (Authors copy): Narrative intelligence in nursing: storying patient lives in dementia care. Nursing Inquiry. Accepted 27/03/18

Webster, J., \& Haight, B. (2002). Critical advances in reminiscence work: from theory to practice. New York: Springer. 
Witham G \& Haigh C (Authors copy): Narrative intelligence in nursing: storying patient lives in dementia care. Nursing Inquiry. Accepted 27/03/18

Table 1: Medieval constructions of memory (Katz, 2013).

1. Memory is an act of agency and imagination, not simply a passive and cognitive process of input and output memory.

2. Memory is a force that intersects individuals, environmental and worldly forces beyond and between individuals, across communal spaces and collective activities.

3. Memory can be expressed on and through the body.

4. Memory loss is not necessarily a disease but a contingent condition of growing older.

5. Memory is emotional as well as cerebral and to separate the two means failing to understand memory as an 'act' as well as a 'science'. 
Witham G \& Haigh C (Authors copy): Narrative intelligence in nursing: storying patient lives in dementia care. Nursing Inquiry. Accepted 27/03/18

Table 2: Charon (2006) Five narrative features of medicine.

1. Temporality refers to the time needed to generate "healing", to engage in collective narratives through collaboration and listening.

2. Singularity highlights the unique nature of narrative encounters in both their originality and irreproducibility.

3. Causality calls for a narrative structure and emplotment(s) that contextualise stories and make them culturally recognisable.

4. Intersubjectivity is essentially the interaction between two individuals. A meeting between teller and listener.

5. Ethicality is imbued within narrative approaches since the coda of stories often hinges on a call to ethical living as either a question or answer. 